\title{
Blood pressure management in acute stroke
}

\author{
Jason P Appleton, Nikola Sprigg, Philip M Bath
}

To cite: Appleton JP, Sprigg N, Bath PM. Blood pressure management in acute stroke. Stroke and Vascular Neurology 2016;1: e000020. doi:10.1136/svn2016-000020

Received 31 March 2016 Revised 20 May 2016 Accepted 21 May 2016
CrossMark

Stroke Trials Unit, Division of Clinical Neuroscience, University of Nottingham, Nottingham, UK

Correspondence to Professor Philip M Bath; Philip.bath@nottingham.ac.uk

\section{ABSTRACT}

Blood pressure (BP) is elevated in $75 \%$ or more of patients with acute stroke and is associated with poor outcomes. Whether to modulate BP in acute stroke has long been debated. With the loss of normal cerebral autoregulation, theoretical concerns are twofold: high BP can lead to cerebral oedema, haematoma expansion or haemorrhagic transformation; and low BP can lead to increased cerebral infarction or perihaematomal ischaemia. Published evidence from multiple large, high-quality, randomised trials is increasing our understanding of this challenging area, such that BP lowering is recommended in acute intracerebral haemorrhage and is safe in ischaemic stroke. Here we review the evidence for BP modulation in acute stroke, discuss the issues raised and look to on-going and future research to identify patient subgroups who are most likely to benefit.

\section{BACKGROUND}

Stroke has a global incidence of 15 million people per year, is the third leading cause of death and is the most common cause of disability in the western world. ${ }^{1}$ High-blood pressure (BP) is the leading modifiable risk factor for both ischaemic and haemorrhagic stroke $^{2}$ affecting 1 billion people worldwide. ${ }^{3}$ In acute stroke, $75 \%$ of patients have high BP and $50 \%$ of those have a prior history of hypertension. ${ }^{4}$ Although BP spontaneously falls in two-thirds of patients in the first week following stroke, ${ }^{4}$ one-third remain hypertensive and have an increased risk of a poor outcome. ${ }^{6}$ Data from the first International Stroke Trial demonstrated a U-shaped relationship between baseline systolic BP (SBP) and outcome, such that both high and low SBP were independently associated with increased early death and late death or dependency. ${ }^{7}$ In addition, high SBP is associated with an increased risk of early stroke recurrence. ${ }^{78}$ Post hoc analyses from several acute stroke clinical trials suggest that as well as increased SBP, other haemodynamic variables including higher peak SBP, mean arterial pressure (MAP), pulse pressure and increased SBP variability, are each associated with poor functional outcome, ${ }^{9}$ early neurological deterioration, ${ }^{10}$ recurrent stroke and death. ${ }^{11}$

The acute hypertensive response seen in stroke has numerous potential causes including: fluctuations in, or elevation of, preexisting hypertension; infection; pain, for example, due to urinary retention; stress related to hospitalisation; activation of cortisol, natriuretic peptide, renin-angiotensinaldosterone and sympathetic neuroendocrine systems; impaired cardiac baroreceptor sensitivity; and raised intracranial pressure (Cushing's reflex). ${ }^{12-15}$ Although low BP is far less common in acute stroke, it is associated with a poor outcome. ${ }^{7}$ Potential causes include sepsis, cardiac arrhythmias, heart failure and ischaemia, hypovolaemia and aortic dissection. ${ }^{16}$

Normal cerebral autoregulation, which maintains cerebral blood flow (CBF) despite fluctuations in cerebral perfusion pressure (CPP) between 50 and $150 \mathrm{~mm} \mathrm{Hg}$, is impaired in acute stroke resulting in cerebral perfusion having a linear relationship with CPP and therefore MAP. ${ }^{17}$ Rapid, large falls in BP could reduce CBF leading to extension of cerebral infarction, ${ }^{18}$ or perihaematomal ischaemia. ${ }^{19}$ Equally, with higher BP there is increased risk of haematoma expansion in intracerebral haemorrhage (ICH), haemorrhagic transformation in animal models of ischaemic stroke (IS) and cerebral oedema, in both types of stroke. ${ }^{6} 20$

The debate surrounding whether high $\mathrm{BP}$ should or should not be treated in the context of acute stroke started over 30 years ago ${ }^{21} 22$ and despite large clinical trials the answer remains largely unclear. In this review, we discuss the evidence for BP modulation in acute stroke, the challenges and issues raised, and look to on-going and future trials that may provide some clarity in this controversial area.

\section{CLASS ACTION}

A variety of BP modulating agents have been assessed in the context of acute stroke (table 1). ${ }^{23}$ 


\section{$\alpha$-2-adrenoreceptor agonists}

The $\alpha$-2-adrenoreceptor agonist, clonidine, was tested in a small randomised controlled trial (RCT), which allocated 16 participants with middle cerebral artery infarction within 72 hours of onset and high baseline BP (SBP 170-220 mm Hg, diastolic BP (DBP) 95-120 mm Hg) to nicardipine $20 \mathrm{mg}$, captopril $12.5 \mathrm{mg}$, clonidine $0.1 \mathrm{mg}$, or placebo given every 8 hours for 3 days. ${ }^{24}$ BP fell in all groups but there was no significant difference in BP between the two main groups and no difference in stroke outcome, measured using the National Institutes of Health Stroke Scale (NIHSS), over the 3 days of treatment. To date, no large RCTs have assessed the use of $\alpha$-2-adrenoreceptor agonists in acute stroke.

\section{ACE inhibitors}

In three small RCTs of acute IS (AIS) oral perindopril, ${ }^{43}$ lisinopril $^{44}$ and captopril ${ }^{24}$ independently reduced BP, while preserving CBF, although no differences in neurological impairment (NIHSS) or functional outcome (modified Rankin Scale (mRS)) were seen between groups. ${ }^{44}$

The Controlling Hypertension and Hypotension Immediately Post-Stroke (CHHIPS) trial ${ }^{25}$ randomised 179 patients with either IS or ICH within 36 hours of ictus and SBP $>160 \mathrm{~mm} \mathrm{Hg}$ to oral labetalol $(50 \mathrm{mg})$, lisinopril $(5 \mathrm{mg}$ ) or placebo in those without dysphagia, or intravenous labetalol $(50 \mathrm{mg})$, sublingual lisinopril (5 mg), or placebo in those with dysphagia. Dose escalation occurred if participants did not reach target SBP (145-155 or $15 \mathrm{~mm} \mathrm{Hg}$ reduction) at 4 and 8 hours postrandomisation. Lisinopril reduced mean BP by 14/ $7 \mathrm{~mm} \mathrm{Hg}$ compared with placebo between randomisation and 24 hours. Following 14 days of treatment there was no difference in functional outcome $(\mathrm{mRS}>3)$ between treatment and control (relative risk (RR) 1.03, 95\% CI 0.8 to $1.33, \mathrm{p}=0.82$ ), although lisinopril was safe with no increased reporting of serious adverse events.

In the prehospital environment the Paramedic Initiated Lisinopril For Acute Stroke Treatment (PIL-FAST) study randomised 14 patients with new unilateral arm weakness within 3 hours of onset and SBP $>160 \mathrm{~mm} \mathrm{Hg}$ to either sublingual lisinopril $(5 \mathrm{mg})$ or placebo for a total of 7 days. ${ }^{26} \mathrm{BP}$ fell in the lisinopril group compared to control by hospital admission and persisted for the duration of treatment. As a feasibility trial it was successful but was not powered to assess efficacy.

\section{Angiotensin receptor antagonists}

The Acute Candesartan Cilexetil Therapy in Stroke Survivors (ACCESS) study $^{27}$ randomised 339 participants with IS and elevated BP $(\geq 180 / 105 \mathrm{~mm} \mathrm{Hg})$ to 7 days of oral candesartan or placebo within 36 hours of admission. Mortality at 12 months and cardiovascular events (secondary outcome) were significantly reduced in the candesartan arm, although there was no significant effect on functional outcome (Barthel index (BI), primary outcome) at 3 months, or on BP throughout the 12 months of the trial.

A post hoc subgroup analysis of the multinational Prevention Regimen for Effectively Avoiding Second Strokes (PRoFESS) trial ${ }^{28}$ examined the effect of adding telmisartan versus placebo to standard antihypertensive management in 1360 patients with mild IS recruited within 72 hours of ictus. Telmisartan lowered SBP and DBP by $6-7$ and $2-4 \mathrm{~mm} \mathrm{Hg}$ respectively compared with placebo and was safe with no excess of adverse events. However, telmisartan did not influence functional outcome (mRS at day 30, primary outcome) or death, stroke recurrence and cardiovascular events at days 7, 30 or 90. In contrast to the ACCESS study, PRoFESS participants had lower BP at randomisation, milder strokes, enhanced antihypertensive therapy, were recruited later (58 vs 29 hours) and had a longer period of treatment (30 months vs 7 days), which may account for the dissimilar findings between the trials.

Following ACCESS, the Scandinavian Candesartan Acute Stroke Trial (SCAST) ${ }^{29}$ recruited 2029 participants with acute stroke (IS and ICH) within 30 hours of onset and SBP $\geq 140 \mathrm{~mm} \mathrm{Hg}$. Patients were randomised to either candesartan $4 \mathrm{mg}$ with dose escalation up to $16 \mathrm{mg}$, or placebo for 7 days. BP fell in both groups over the treatment period and was significantly lower in the candesartan arm compared to placebo (day 7 mean BP: $147 / 82$ vs $152 / 84 \mathrm{~mm} \mathrm{Hg}$ ). Co-primary end points were measured at 6 months: a composite of vascular death, myocardial infarction and stroke was neutral; and functional outcome measured by a shift in mRS suggested a higher risk of poor outcome in those randomised to candesartan, but was not statistically significant given the two primary outcomes (adjusted common OR (acOR) $1.17,95 \%$ CI 1.00 to $1.38, \mathrm{p}=0.048)$. A prespecified subgroup analysis of those with ICH $(n=274)$ also found that candesartan was associated with an increased risk of poor outcome (acOR 1.61, 95\% CI 1.03 to 2.50, $\mathrm{p}=0.036){ }^{45}$

Several smaller, underpowered trials have assessed candesartan, ${ }^{46}$ irbesartan, ${ }^{47}$ telmisartan, ${ }^{30}$ and valsartan ${ }^{48}$ in AIS. Telmisartan did not alter CBF or BP acutely. ${ }^{30}$ The Valsartan Efficacy oN modesT blood pressUre Reduction in acute ischaemic stroke (VENTURE) trial, ${ }^{48}$ randomised 393 South Korean patients with AIS within 24 hours of onset and SBP $150-185 \mathrm{~mm} \mathrm{Hg}$ to oral valsartan $80 \mathrm{mg}$ daily with dose escalation, or placebo for 7 days. Valsartan significantly reduced mean DBP at day 7 compared with placebo ( 83.1 vs $84.8 \mathrm{~mm} \mathrm{Hg}$ ), while SBP was not significantly reduced. The primary outcome of death or dependency at 90 days $(\mathrm{mRS}>3)$ was neutral, but early neurological deterioration within 7 days was significantly higher in the valsartan group ( $16.6 \%$ vs $6 \%$, OR $2.43,95 \%$ CI 1.25 to $4.73, \mathrm{p}=0.008$ ); mainly due to stroke progression in those with large artery atherosclerosis as the cause of their stroke and angiographically confirmed large-artery stenosis or occlusion. 


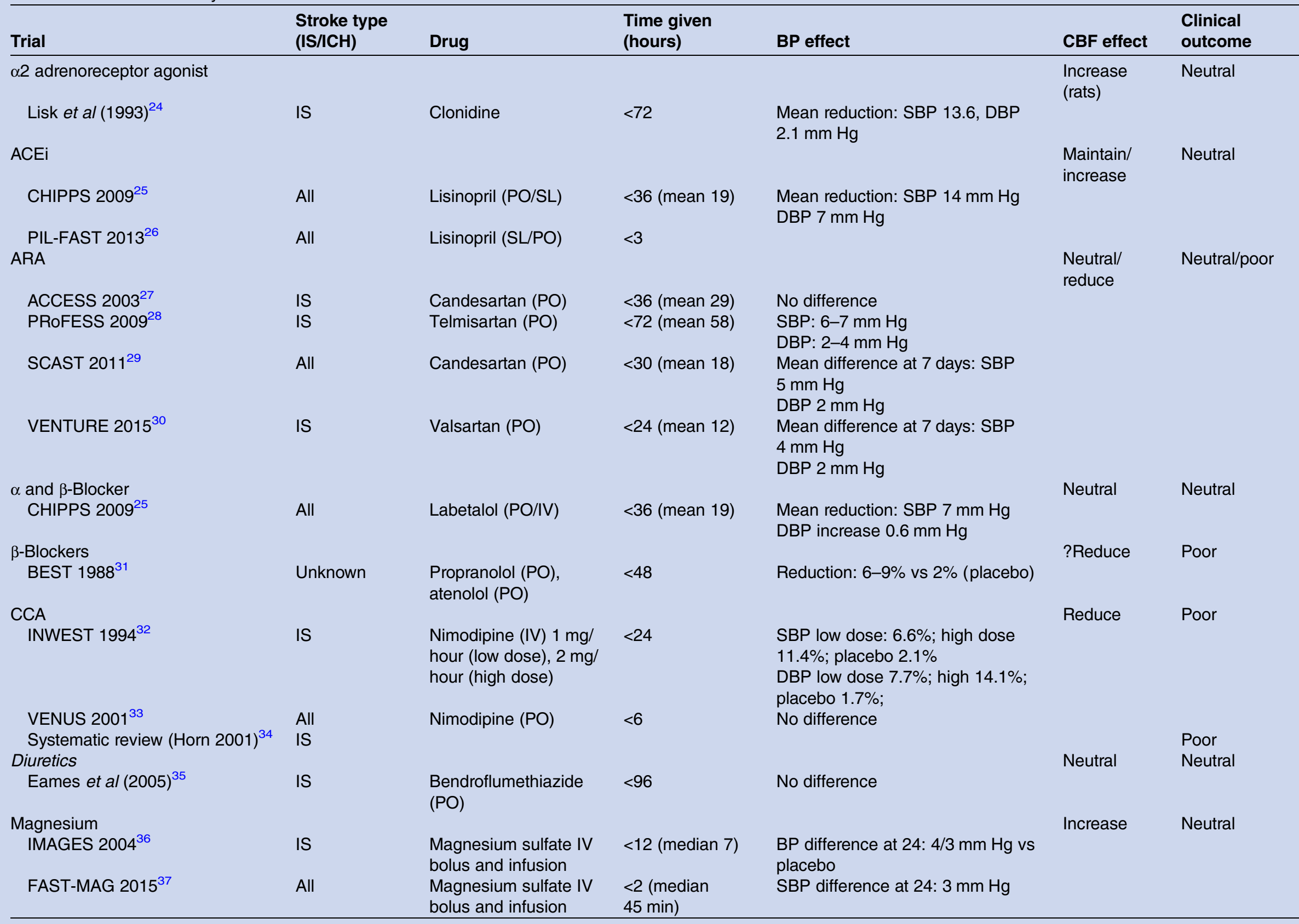




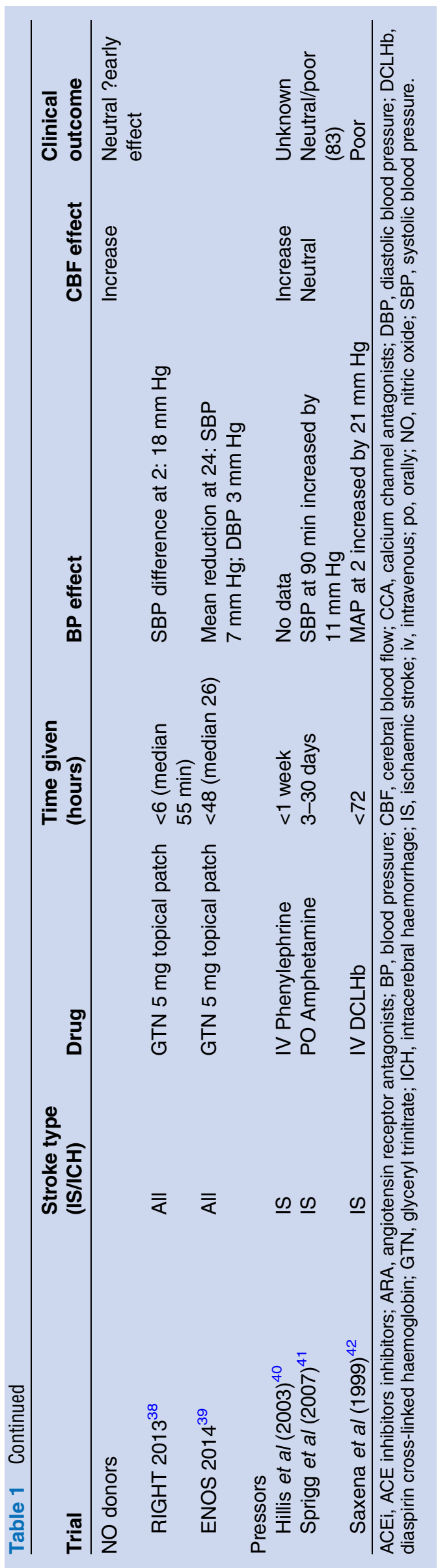

These neutral and negative findings may indicate that angiotensin receptor antagonists (ARAs) have undesirable properties in acute stroke or that gradual and late treatment of $\mathrm{BP}$ is 'too little too late', thus reducing cerebral perfusion and increasing brain injury.

\section{$\beta$-blockers}

The single-centre $\beta$-blocker stroke (BEST) trial ${ }^{31}$ randomised 302 patients with clinically diagnosed strokes within 48 hours of onset to oral propranolol, atenolol or placebo. There was a greater fall in mean BP in the first 24 hours of treatment (6-9\% vs 2\%) and an increase in early and later death in those assigned to $\beta$-blockers compared to placebo. The negative inotropic effects of $\beta$-blockers may worsen cerebral perfusion in acute stroke and thus explain this finding, although pathophysiological trial data are lacking (table 2).

In those randomised to labetalol (a mixed $\alpha$ and $\beta$ adrenergic antagonist) in the CHHIPS trial, ${ }^{25}$ SBP fell by $7 \mathrm{~mm} \mathrm{Hg}$ at 24 hours. In contrast to the BEST trial, labetalol was safe with no increase in serious adverse events, early neurological deterioration or death. Overall, the active treatment group (labetalol and lisinopril combined) had reduced 90-day mortality compared to the placebo group (HR $0.40,95 \%$ CI 0.2 to 1.0 , $\mathrm{p}=0.05$ ) but the study was not powered for this outcome.

\section{Calcium channel antagonists}

Early studies showed significant drops in BP in patients who received nimodipine ${ }^{66}$ or nicardipine, ${ }^{24}$ with the latter suggesting that large drops in $\mathrm{BP}$ due to nicardipine were associated with reduced regional $\mathrm{CBF}$ to infarcted tissue. Contrary to this, other small trials reported positive results of oral ${ }^{67} 68$ and intravenous nimodipine ${ }^{69}$ on long-term recovery in AIS, prompting the need for a larger RCT.

The Intravenous Nimodipine West European Stroke Trial (INWEST) ${ }^{32}$ randomised 295 patients with AIS within 24 hours of onset to intravenous nimodipine at $1 \mathrm{mg}$ /hour (low dose) or $2 \mathrm{mg} /$ hour (high dose) for 5 days then $120 \mathrm{mg}$ daily (orally) for a total of 21 days, or placebo. Recruitment was stopped early due to statistically significant unfavourable functional outcomes (BI and Orgogozo neurological impairment scale) in the nimodipine groups compared with placebo at both 21 days and 6 months. Over the first 2 days, mean BP significantly fell from baseline in the treatment arms compared with placebo. ${ }^{70}$ In a subsequent analysis, DBP reduction in the high-dose treatment arm was associated with a poor functional outcome at day 21, while those who received high-dose nimodipine and had a large $(\geq 20 \%)$ fall in DBP had an increased risk of death or dependency and death at day $21 .^{70}$ A similar but unpublished trial in the USA had comparable results. ${ }^{71}$

A further trial of oral nimodipine recruited 454 patients within 6 hours of stroke ictus in primary care. ${ }^{33}$ At 24 hours there was no significant difference in BP between the nimodipine and control groups, and the 


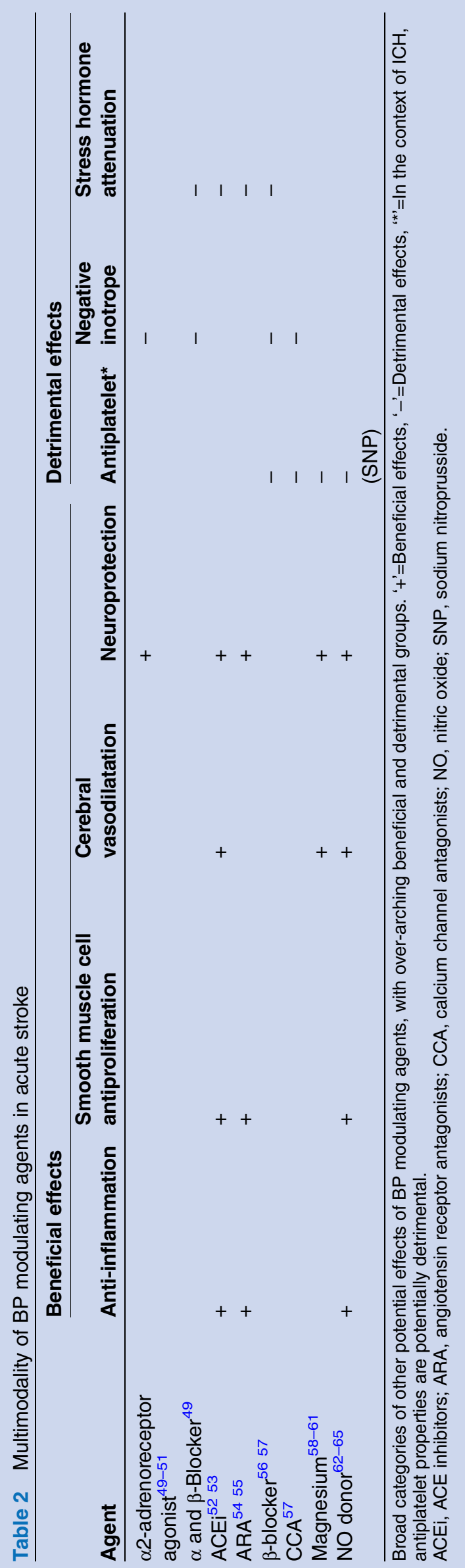

primary outcome of death or dependency $(\mathrm{mRS}>3)$ at 3 months was neutral (RR 1.2, 95\% CI 0.9 to 1.6). This trial was stopped early because a Cochrane systematic review involving 7665 patients from 29 trials of calcium channel antagonists (CCA) in AIS revealed no treatment effect on functional outcome or death at the end of follow-up. ${ }^{72}$ Interestingly, a subgroup analysis of unpublished and methodologically sound trials yielded a statistically significant unfavourable treatment effect indicative of publication bias (RR 1.14, CI 95\% 1.0 to $1.3)$; overall, good quality trials produced a statistically significant negative treatment effect (RR 1.09, 95\% CI 1.02 to 1.16$).{ }^{34}$ Unfortunately, much of the drive to test CCA, especially nimodipine, was driven by early positive data. ${ }^{67-69} 73$

\section{Diuretics}

There is limited data on diuretics in acute stroke. ${ }^{23}$ One small RCT randomised 37 hypertensive patients with AIS within 96 hours of onset to bendroflumethiazide (a thiazide-like diuretic) $2.5 \mathrm{mg}$ daily or placebo for 7 days. ${ }^{35}$ Although mean SBP was lower in the treatment group compared with placebo within 70 hours of randomisation (156 vs $176 \mathrm{~mm} \mathrm{Hg}$ ), there was no difference in BP between the arms at day 7. Measures of CBF and cardiac baroreceptor sensitivity showed no significant change between groups at either time point in the trial, suggesting that bendroflumethiazide is an ineffective agent for use in acute patients with stroke.

\section{Magnesium}

A systematic review of several small pilot studies assessing magnesium in acute stroke reported a non-significant reduction in death or disability in patients treated with magnesium (OR $0.73,95 \%$ CI 0.38 to 1.41 ) ${ }^{74}$ A large RCT allocated 2589 patients with AIS within 12 hours of onset to intravenous magnesium sulfate slow bolus $(16 \mathrm{mmol})$ followed by infusion $(65 \mathrm{mmol})$ over 24 hours, or placebo. ${ }^{36}$ Although BP fell by $4 / 3 \mathrm{~mm} \mathrm{Hg}$ between baseline and 24 hours in the magnesium group compared with placebo, the only significant difference in $\mathrm{BP}$ was during the initial infusion. The primary outcome of death and disability at day 90 (BI $<95$ and mRS $>1$ combined) was neutral, but there was a trend towards increased mortality in the magnesium group (HR $1.18,95 \%$ CI 0.97 to $1.42, \mathrm{p}=0.098$ ). In a prespecified subgroup of non-cortical strokes, magnesium significantly reduced death and disability (OR $0.75,95 \% 0.58$ to $0.97, \mathrm{p}=0.011$ ); a finding supported by a post-hoc analysis where those with lacunar stroke had reduced death and disability at day 90 (OR $0.7,95 \% \quad 0.53$ to 0.92 , $\mathrm{p}=0.0046)$. Patients who received magnesium within 3 hours of onset had a trend towards a better outcome (OR $0.66,95 \% 0.25$ to $1.7, \mathrm{p}=0.46$ ).

The Field Administration of Stroke Therapy-Magnesium (FAST-MAG) trial $^{37}$ sought to assess magnesium in this shorter time window by recruiting 1700 patients with presumed stroke within 2 hours of ictus to intravenous 
magnesium bolus followed by infusion, or placebo. SBP fell in both groups over the first 48 hours but those on treatment had a significantly lower SBP $(\sim 3 \mathrm{~mm} \mathrm{Hg}$ difference) at the end of the bolus dose and from 20 to 32 hours after starting the maintenance infusion. Although prehospital initiation of magnesium was safe, there was no significant shift in mRS at day 90 (primary outcome).

\section{Nitric oxide donors}

In three small RCTs in acute stroke, transdermal glyceryl trinitrate (GTN) lowered BP, pulse pressure and peak SBP while maintaining CBF and improving arterial compliance. ${ }^{65} 7677$ A small ambulance-based feasibility trial of transdermal GTN administered within 4 hours of symptom onset revealed an improvement in functional outcome at 90 days, measured as a shift in mRS by 1 point $(p=0.04) .{ }^{38}$ None of these trials were powered for functional outcome; this was assessed in the large Efficacy of Nitric Oxide in Stroke (ENOS) trial. ${ }^{39}$

ENOS randomised 4011 patients with AIS or ICH within 48 hours of onset and high SBP $(140-220 \mathrm{~mm} \mathrm{Hg})$ to transdermal GTN $5 \mathrm{mg}$ patches or placebo for 7 days. In addition, those participants on antihypertensive agents immediately prior to their stroke were randomised to stop or continue their medication, in a partial-factorial design. ${ }^{39}$ GTN significantly reduced both SBP and DBP day 1 after randomisation compared to placebo (mean difference: 7 and $3 \mathrm{~mm} \mathrm{Hg}$, respectively, $\mathrm{p}<0.001$ ) but there was no statistically significant difference from day 3 onwards. Overall, GTN was safe in both IS and ICH. Although the primary outcome of mRS at day 90 was neutral (acOR 1.0, 95\% CI 0.91 to 1.13 , $\mathrm{p}=0.83$ ), a prespecified subgroup analysis found that in those recruited in $<6$ hours from ictus, GTN was associated with a favourable shift in mRS (acOR 0.51, 95\% 0.32 to $0.8, \mathrm{p}=0.004$ ), less death and improved cognition, disability, mood and quality of life. ${ }^{77}$ Beneficial effects were seen in patients with IS (including those receiving thrombolysis) and ICH. $^{78}$

\section{Pressor therapy}

Several small studies have assessed the role of pressor therapy in AIS. ${ }^{23} 79$ One trial assessed intravenous phenylephrine versus conventional management in 15 patients with AIS within 1 week of ictus, $>20 \%$ diffusionperfusion mismatch on MRI and normotension (SBP $<140 \mathrm{~mm} \mathrm{Hg}$ ). ${ }^{40}$ Phenylephrine was titrated to increase MAP by $10-20 \%$ and maintained for up to 72 hours. NIHSS and cognitive scores, and volume of hypoperfused tissue on MRI, improved in the treatment group with no significant adverse events, but there was no assessment of functional outcome. The aforementioned CHHIPS trial had a pressor arm, which sought to assess phenylephrine in hypotensive patients with IS, but grossly under-recruited (one participant only, who received placebo).$^{80}$ Similarly, an unpublished trial of dobutamine only managed to recruit three patients.
Diaspirin cross-linked haemoglobin (DCLHb), a cellfree haemoglobin-based oxygen-carrying solution that scavenges $\mathrm{NO},{ }^{81}$ was compared with saline in 85 patients with AIS within 18 hours of onset. ${ }^{42}$ DCLHb caused a rapid rise in $\mathrm{BP}$ and more serious adverse events, disability (BI), death and poor functional outcome (mRS) at 3 months than control. In a small RCT of 33 patients within 1 month of $\mathrm{IS}^{41}$ amphetamine raised $\mathrm{BP}$ and heart rate but had no impact on motor function or functional outcome. Although amphetamine was associated with a trend to improved motor function after IS in a systematic review, there was a non-significant increase in death, raising doubts over its safety. ${ }^{82}$ Other potential agents including norepinephrine (noradrenaline), epinephrine (adrenaline) and dopamine have no significant evidence base. ${ }^{79}$

\section{TARGETTING BP IN ACUTE STROKE}

An alternative avenue of research has focused on whether aiming for a BP target in acute stroke, regardless of the agent(s) used, improves outcome.

\section{Ischaemic stroke}

The China Antihypertensive Trial in Acute Ischaemic Stroke (CATIS) ${ }^{83}$ recruited 4071 patients with AIS with raised SBP (140-220 $\mathrm{mm} \mathrm{Hg}$ ) within 48 hours of onset and randomised them to either BP lowering (SBP $10-25 \%$ reduction within 24 hours and $\mathrm{BP}<140 /$ $90 \mathrm{~mm} \mathrm{Hg}$ within 7 days) or control (no antihypertensive medication). Although a specific BP-lowering regimen was not being assessed they suggested first-line (intravenous ACEi), second-line (oral CCA) and third-line (oral diuretic) medications. Mean SBP fell by $13 \%$ within 24 hours of randomisation in the treatment group, compared with $7 \%$ in the control population. At 7 days, mean SBP in the treatment and control arms was 137 and $147 \mathrm{~mm} \mathrm{Hg}$ respectively. The primary outcome of $\mathrm{mRS} \geq 3$ at 14 days or hospital discharge and secondary outcome of $\mathrm{mRS}$ at day 90 were neutral. A subgroup analysis of time to treatment found that those randomised to BP lowering 24 hours or longer after ictus had a significant reduction in death or dependency at 3 months (OR $0.73,95 \%$ CI 0.55 to $0.97, \mathrm{p}=0.03$ ). ${ }^{83}$

There are several points to mention. First, the recruits had minor strokes (median NIHSS 4) resulting in 66\% of the control population being independent at 2 weeks and therefore reducing the potential for the intervention to show benefit. Second, patients with large vessel carotid disease were omitted from the trial. And last, patients receiving thrombolysis were excluded, further limiting the trial's generalisability. ${ }^{83}$

\section{Intracerebral haemorrhage}

In a small feasibility study of patients with ICH within 8 hours of symptom onset, aggressive BP lowering (MAP $<110 \mathrm{~mm} \mathrm{Hg}$ ) was safe with no difference in rates of early neurological deterioration, haematoma expansion 
or cerebral oedema. $^{84}$ The concern surrounding whether aggressive BP lowering compromises perihaematoma CBF was addressed in the Intracerebral Haemorrhage Acutely Decreasing Arterial Pressure Trial (ICH-ADAPT) ${ }^{85}$ Seventy-five patients with spontaneous ICH within 24 hours of onset and high BP (SBP $\geq 150 \mathrm{~mm} \mathrm{Hg}$ ) were randomised to a target SBP of $<150$ or $<180 \mathrm{~mm} \mathrm{Hg}$ within 1 hour of randomisation. Two hours after recruitment CT perfusion imaging revealed reduced $\mathrm{CBF}$ and cerebral blood volume within the perihaematoma region compared with the contralateral homologous area in all patients. There was no significant difference in relative $\mathrm{CBF}$ between the groups, indicating that aggressive BP reduction in ICH did not, at least in this study, precipitate perihaematomal ischaemia. ${ }^{85}$

Early BP lowering in the Intensive Blood Pressure Reduction in Acute Cerebral Haemorrhage Trial (INTERACT) $^{86}$ involving 404 patients was safe, feasible and seemed to reduce haematoma growth. Similarly, $\mathrm{BP}$ reduction within 6 hours in the Antihypertensive Treatment of Acute Cerebral Haemorrhage (ATACH) ${ }^{87}$ study was safe. The magnitude of SBP lowering was associated with less haematoma expansion and improved functional outcome. ${ }^{88}$ The largest trial of intensive BP lowering in ICH, INTERACT $2,{ }^{89}$ recruited 2839 patients within 6 hours of onset with high SBP (150-220 $\mathrm{mm} \mathrm{Hg}$ ) and randomised them to guideline therapy ( $\mathrm{SBP}<180 \mathrm{~mm} \mathrm{Hg}$ ) or intensive therapy (SBP $<140 \mathrm{~mm} \mathrm{Hg}$ within 1 hour) for 7 days using oral or intravenous agents at the discretion of the local investigator. At 1 hour, a third of patients in the intensive arm achieved the target SBP of $<140 \mathrm{~mm} \mathrm{Hg}$ with a mean SBP of $150 \mathrm{~mm} \mathrm{Hg}$, compared with $164 \mathrm{~mm} \mathrm{Hg}$ in the guideline group. The primary outcome of death or major disability (mRS $\geq 3$ at 90 days) was neutral, but a prespecified ordinal shift analysis of mRS revealed a favourable shift in those randomised to intensive BP lowering (OR $0.87,95 \%$ CI 0.77 to 1.00 , $\mathrm{p}=0.04$ ). In addition, better outcomes were seen in those with larger BP reductions within 1 hour of randomisation. ${ }^{90}$ Intensive BP reduction was safe with no difference in death or other serious adverse events between groups. ${ }^{89}$

The use of mannitol in $62 \%$ of INTERACT2 participants is unclear given that the overall 24 hours median haematoma volume was $20 \mathrm{~mL}$, making intracranial hypertension unlikely. The myriad combinations of antihypertensive agents used in the trial included one rarely used in the West (Urapidil) and others with potentially negative or harmful effects, which may have confounded the BP-lowering effect. ${ }^{91}$

While INTERACT2 did not show any change in haematoma expansion with aggressive BP lowering, a meta-analysis of four of the above trials ${ }^{84-86} 89$ found that intensive BP lowering in acute ICH appeared safe with a tendency towards improved functional outcome; an effect which may have been mediated through attenuation of haematoma expansion observed at 24 hours in both unadjusted and adjusted models. ${ }^{92}$ Furthermore, a post hoc analysis of INTERACT2 revealed that intensive BP lowering with greater SBP reduction prevented haematoma growth at 24 hours. ${ }^{93}$

\section{ISSUES}

\section{To treat or not to treat?}

Guidelines suggest that BP lowering in acute stroke should be postponed for days or even weeks unless $\mathrm{BP}$ is grossly elevated $(>220 / 120 \mathrm{~mm} \mathrm{Hg})$, or $>200 / 100$ with concomitant evidence of acute kidney injury, aortic dissection, cardiac ischaemia, hypertensive encephalopathy or pulmonary oedema. ${ }^{94-96}$

\section{Thrombolysis for hyper-acute ischaemic stroke}

In the context of thrombolysis in AIS, BP must be $<185$ / $110 \mathrm{~mm} \mathrm{Hg}$ prior to administration of alteplase, and $<180 / 105 \mathrm{~mm} \mathrm{Hg}$ for the following 24 hours; suggested methods involve using intravenous labetalol, nicardipine or nitroprusside. ${ }^{94}$ Unfortunately there is a paucity of evidence and this recommendation is based on expert opinion with extrapolation from trials of thrombolysis in myocardial infarction. ${ }^{97} 98$ Observational data from the Safe Implementation of Thrombolysis in Stroke (SITS) register ${ }^{99} 100$ revealed that a higher SBP post-thrombolysis is associated with symptomatic ICH and poor outcome. A U-shaped relationship was seen between SBP 2-24 hours after thrombolysis and major disability and death, with the most favourable outcomes occurring in those with SBP 141-150 mm Hg. ${ }^{100}$ The on-going Enhanced Control of Hypertension and Thrombolysis in Stroke Study (ENCHANTED $)^{101}$ will provide insight into whether acute intensive lowering of BP (target SBP 130-140 mm Hg) has superior efficacy and lower risk of ICH than guideline management $(\mathrm{SBP}<180 \mathrm{~mm} \mathrm{Hg})$.

\section{Intracerebral haemorrhage}

In ICH, both American ${ }^{102}$ and European ${ }^{103}$ guidelines recommend acute lowering of SBP to $\leq 140 \mathrm{~mm} \mathrm{Hg}$ within 6 hours of onset. This guidance is largely driven by the results of the INTERACT2 trial. ${ }^{89}$

\section{Race and ethnicity}

Demographics are important and especially relevant in a cosmopolitan global community. For example, Chinese patients with stroke tend to be younger, smoke more, have increased intracranial atherosclerosis, less cervical atherosclerosis and a higher risk of ICH than their Caucasian counterparts. ${ }^{104} 105$ Hence, demographic similarities and differences should be considered in both future trials and individual patient data meta-analyses.

\section{Time to treatment}

In a recent Cochrane review, lowering BP in 15432 patients with acute stroke did not improve outcome regardless of 
stroke type, or drug class and BP target used..$^{23}$ However, in those who received treatment within 6 hours of stroke onset (INTERACT2 and RIGHT), there was a tendency towards a shift to less death or dependency, and improved quality of life. ${ }^{38} 89$ All drug classes described above lowered $\mathrm{BP}$, with greater reductions seen in ICH than patients with AIS $(-11.8 /-5.1$ vs $-7 /-3.1 \mathrm{~mm} \mathrm{Hg})$. Smaller BP changes occurred in patients recruited after 48 hours of onset, while the largest $\mathrm{BP}$ reduction was seen in those recruited earliest. Importantly, large falls in BP $(>20 \%)$, especially in AIS, were associated with a poor outcome. ${ }^{23}$

A subsequent subgroup analysis of ENOS patients randomised to GTN within 6 hours adds weight to the argument for early treatment with reduced death or dependency, less death and improved cognition, disability, mood and quality of life. ${ }^{77}$ It is unclear whether this may represent a generic effect of early BP lowering or a specific effect of GTN. In contrast, other interventions namely ARA, $\beta$-blockers and CCA may be detrimental (table 2). ${ }^{29} 31344572$

Time is important: ultra-acute treatment of BP (intensive BP lowering or use of an appropriate agent) within the first few hours of symptoms in the prehospital setting is a vital avenue to explore further. Non-oral routes of administration, such as transdermal, sublingual and intravenous, would be preferable in this context, given the need for a swallowing assessment to rule out dysphagia. Of these, transdermal GTN, ${ }^{38}$ sublingual lisinopril, ${ }^{26}$ and intravenous magnesium, ${ }^{37}$ have been assessed in the prehospital environment and found to be safe. While transdermal preparations can be easily applied and removed according to clinical need, intravenous administration of BP-lowering agents require intensive monitoring. On-going (RIGHT-2: ISRCTN26986053) and planned trials of transdermal GTN in ultra-acute stroke will assess efficacy in the field.

\section{BP management in carotid disease and large vessel occlusion}

High BP is commonly seen in patients with AIS due to carotid artery stenosis. ${ }^{106}$ Owing to dysfunctional cerebral autoregulation concerns are twofold: a higher systemic BP will result in a higher cerebral perfusion pressure increasing the risk of cerebral oedema and potential for haemorrhagic transformation; while lowering BP may reduce CBF resulting in infarct extension. ${ }^{6}$

A prespecified subgroup analysis from SCAST of patients with carotid imaging $(\mathrm{n}=993(57 \%))$, revealed that those with severe unilateral stenosis $(\geq 70 \%)$ who received candesartan had a trend towards increased risk of stroke progression and poor functional outcome, although the CI were wide. ${ }^{107}$ Whether this was due to a specific effect of candesartan, or to BP lowering per se remains unclear. Of the 2038 participants in ENOS with carotid imaging data, GTN was safe with no evidence of harm across all levels of ipsilateral carotid stenosis. ${ }^{39}$

Patients with bilateral severe carotid stenosis pose another dilemma. A meta-analysis of three trials found that in patients with bilateral severe stenosis $(\geq 70 \%)$, a lower BP was associated with higher stroke recurrence (SBP <130 mm Hg: HR 5.97, 95\% CI 2.43 to 14.68, $\mathrm{p}<0.001){ }^{106}$ Although bilateral carotid stenosis is uncommon, caution regarding BP lowering in this group seems warranted pending further data.

With the advent and proven effectiveness of endovascular intervention for proximal anterior circulation vessel occlusions in AIS, ${ }^{108}$ numerous questions remain unanswered, including how BP should be managed before, during and after thrombectomy. At present this is an evidence-free zone. Retrospective data comparing general with local anaesthesia during the procedure found that general anaesthesia, which was often associated with SBP $<140 \mathrm{~mm} \mathrm{Hg}$, was associated with a poor functional outcome $(\mathrm{mRS}>2)$ at 90 days. ${ }^{109}$ Prospective research in this area should prove illuminating.

\section{Continue or stop pre-stroke antihypertensives}

Whether to temporarily stop or continue existing antihypertensive agents early after a patient's stroke is a common clinical question. The Continue or Stop Post-Stroke Antihypertensives Collaborative Study $(\text { COSSACS })^{110}$ randomised 763 patients within 48 hours

Summary box: BP agents of choice in acute stroke

\begin{tabular}{|c|c|}
\hline Acute ischaemic stroke (AIS) & $\begin{array}{l}\text { Avoid large falls (>20\%) in BP. } \\
\text { Aim for gradual BP reduction (5-15\%). }\end{array}$ \\
\hline Intracerebral haemorrhage $(\mathrm{ICH})$ & Rapid lowering of BP to $\leq 140 \mathrm{~mm} \mathrm{Hg}$ within 6 hours of onset. \\
\hline Intravenous agents & Require continuous cardiac monitoring. \\
\hline Labetalol & $\begin{array}{l}10-20 \mathrm{mg} \text { bolus, over } 1-2 \mathrm{~min} \text {. Further boluses can be given } \\
\text { every } 10 \mathrm{~min} \text {, titrated to BP effect (maximum dose } 300 \mathrm{mg} \text { ). } \\
\text { Alternative: labetalol infusion. }\end{array}$ \\
\hline Glyceryl trinitrate & $10-200 \mu \mathrm{g} / \mathrm{min}$ infusion titrated to BP effect. \\
\hline Nicardipine & $\begin{array}{l}\text { Avoid large BP falls in AIS. } \\
5 \mathrm{mg} / \mathrm{hour} \text { infusion titrated to BP effect. }\end{array}$ \\
\hline Sodium nitroprusside & $\begin{array}{l}\text { Avoid in } \mathrm{ICH} \text { due to antiplatelet effects. } \\
0.5 \mu \mathrm{g} / \mathrm{kg} / \mathrm{min} \text { initial dose, infusion then titrated to BP effect. }\end{array}$ \\
\hline Oral agents & Swallowing assessment required, up to $50 \%$ of patients dysphagic. \\
\hline Sublingual agents & Rapidly absorbed, can cause steep falls in BP (limited data). \\
\hline Transdermal agents & Glyceryl trinitrate 5-10 mg/24-hour patch according to BP effect. \\
\hline
\end{tabular}


of stroke to either stop or continue their pre-existing antihypertensive medication for 2 weeks. Those who continued their medication had a lower BP at 2 weeks compared with those who stopped (mean difference $13 / 8 \mathrm{~mm} \mathrm{Hg}$ ). Death or dependency at 2 weeks (mRS $>3$, primary outcome), death, major cardiovascular events and serious adverse events at 6 months did not differ between the two arms. ${ }^{110}$

The partial-factorial ENOS trial ${ }^{39}$ enrolled 2097 patients within 48 hours of stroke onset to continue or stop their pre-stroke antihypertensive drugs for 7 days. Although there was no effect on functional outcome (mRS) at day 90, continuation of pre-stroke BP drugs increased the risk of pneumonia (perhaps due to aspiration), worsened BI and increased cognitive impairment at 90 days.

When pooled data from COSSACS and ENOS were reviewed, continuation of antihypertensives was associated with worse disability (BI) and quality of life but no change in functional outcome (mRS). ${ }^{23}$ This incongruity is perplexing, but may represent chance, outcome bias or indeed be real. If the latter is true and continuing medication is detrimental, what is the mechanism? First, giving medication to dysphagic patients without appropriate enteral access could lead to aspiration and resultant pneumonia. ${ }^{39}$ Second, as ACEi, ARA and $\beta$-blocker drugs attenuate stress hormones, are common preparations used prior to stroke, and are associated with harm when given acutely after stroke (ARA and $\beta$-blockers), ${ }^{29}{ }^{31}$ it may be that continuing them in the acute phase is potentially hazardous. ${ }^{23}$ It therefore seems reasonable to pause existing antihypertensive medication during the acute phase of stroke until patients have suitable enteral access and are medically and neurologically stable. ${ }^{23}$

\section{CONCLUSION}

Despite the recent publication of several large clinical trials and systematic reviews, there are no definitive recommendations that can be drawn regarding BP modulation in AIS. BP should be lowered rapidly in patients with ICH. Although stroke is more common in the older population, trials to date have mostly involved patients with a mean age of $\leq 75$ years. Despite this, there is no suggestion that older patients should not have their BP lowered. ${ }^{89}$ In addition to age, further evidence is needed on whether time of onset, stroke subtype, severity, drug choice (dose, route and timing), and $\mathrm{BP}$ variability influence response to changes in BP. Individual patient data meta-analysis is warranted to aid patient selection by identifying groups who are more or less likely to benefit and to establish whether a certain drug class, dose, route or BP target is optimal. ${ }^{23}$

In summary, antihypertensives should be withheld after stroke until they can be given safely in patients who are neurologically stable. Both early intensive lowering of BP in ICH and early nitrate use in all stroke subtypes are safe and associated with improved functional outcome. Whether these effects are mediated through BP reduction or specific pharmacological effects incorporating neuroprotection and/or reperfusion is unclear. Time seems to be a key factor and so on-going and future hyper-acute and ultra-acute trials are pivotal in testing this hypothesis.

Contributors JPA produced the first draft, which NS and PMB commented and amended. A final version was agreed by all authors. PMB is corresponding author.

Funding JPA is funded by the Health Technology Assessment programme of the National Institutes of Health Research (TARDIS (10/104/24) and TICH-2 (11/129/109) trials), and British Heart Foundation (RIGHT-2 (CS/14/4/30972) trial).

Competing interests PMB was/is chief investigator of the trials involving GTN (RIGHT, ENOS and RIGHT-2), and was a member of the steering committee of the IMAGES trial. He is Stroke Association Professor of Stroke Medicine.

Provenance and peer review Commissioned; externally peer reviewed.

Data sharing statement No additional data are available.

Open Access This is an Open Access article distributed in accordance with the Creative Commons Attribution Non Commercial (CC BY-NC 4.0) license, which permits others to distribute, remix, adapt, build upon this work noncommercially, and license their derivative works on different terms, provided the original work is properly cited and the use is non-commercial. See: http:// creativecommons.org/licenses/by-nc/4.0/

\section{REFERENCES}

1. Mackay J, Mensah G. The Atlas of Heart Disease and Stroke. WHO Library. Geneva: Myriad Editions Ltd. 2004.

2. MacMahon S, Peto R, Cutler J, et al. Blood pressure, stroke and coronary heart disease. Part I, prolonged differences in blood pressure: prospective observational studies corrected for the regression dilution bias. Lancet 1990;335:765-74.

3. Kearney PM, Whelton M, Reynolds K, et al. Global burden of hypertension: analysis of worldwide data. Lancet 2005;365:217-23.

4. Britton M, Carlsson A, de Faire U. Blood pressure course in patients with acute stroke and matched controls. Stroke 1986;17:861-4.

5. Oppenheimer S, Hachinski V. Complications of acute stroke. Lance 1992;339:721-4.

6. Willmot M, Leonardi-Bee J, Bath PMW. High blood pressure in acute stroke and subsequent outcome: a systematic review. Hypertension 2004:43:18-24.

7. Leonardi-Bee J, Bath PMW, Phillips SJ, et al. Blood pressure and clinical outcomes in the International Stroke Trial. Stroke 2002;33:1315-20.

8. Sprigg N, Gray LJ, Bath PMW, et al. Relationship between outcome and baseline blood pressure and other haemodynamic measures in acute ischaemic stroke: data from the TAIST trial. J Hypertens 2006;24:1413-17.

9. Manning L, Hirakawa $\mathrm{Y}$, Arima $\mathrm{H}$, et al. Blood pressure variability and outcome after acute intracerebral haemorrhage: a post-hoc analysis of INTERACT2, a randomised controlled trial. Lancet Neurol 2014;13:364-73.

10. Sare GM, Ali M, Shuaib A, et al. Relationship between hyperacute blood pressure and outcome after ischemic stroke: data from the VISTA Collaboration. Stroke 2009;40:2098-103.

11. Geeganage $C$, Tracy M, England T, et al. Relationship between baseline blood pressure parameters (including mean pressure, pulse pressure, and variability) and early outcome after stroke: data from the Tinzaparin in Acute Ischaemic Stroke Trial (TAIST). Stroke 2011;42:491-3.

12. Robinson TG, James M, Youde J, et al. Cardiac baroreceptor sensitivity is impaired after acute stroke. Stroke 1997;28:1671-6.

13. Alqadri SL, Sreenivasan V, Qureshi Al. Acute hypertensive response management in patients with acute stroke. Curr Cardiol Rep 2013;15:426.

14. Fodstad H, Kelley PJ, Buchfelder M. History of the Cushing reflex Neurosurgery 2006;59:1132-7.

15. Chamorro A, Amaro $S$, Vargas $M$, et al Catecholamines, infection, and death in acute ischaemic stroke. J Neurol Sci 2007;252:29-35. 
16. Sprigg N, Bath PMW. Management of blood pressure in acute stroke. Pract Neurol 2005;5:218-23.

17. Tikhonoff $\mathrm{V}$, Zhang $\mathrm{H}$, Richart $\mathrm{T}$, et al. Blood pressure as a prognostic factor after acute stroke. Lancet Neurol 2009;8:938-48.

18. Owens WB. Blood pressure control in acute cerebrovascular disease. J Clin Hypertens 2011;13:205-11.

19. Qureshi Al. Acute hypertensive response in patients with stroke: pathophysiology and management. Circulation 2008;118:176-87.

20. Fagan SC, Bowes MP, Lyden PD, et al. Acute hypertension promotes hemorrhagic transformation in a rabbit embolic stroke model: effect of labetalol. Exp Neurol 1998;150:153-8.

21. Spence JD, Del Maestro RF. Hypertension in acute ischaemic strokes. Arch Neurol 1985;42:1000-2.

22. Yatsu FM, Zivin J. Hypertension in acute ischaemic strokes. Arch Neurol 1985;42:999-1000.

23. Bath PM, Krishnan K. Interventions for deliberately altering blood pressure in acute stroke. Cochrane Database Syst Rev 2014;10: CD000039.

24. Lisk DR, Grotta JC, Lamki LM, et al. Should hypertension be treated after acute stroke? A randomized controlled trial using single photon emission computed tomography. Arch Neurol 1993;50:855-62.

25. Potter JF, Robinson TG, Ford GA, et al. Controlling hypertension and hypotension immediately post-stroke (CHHIPS): a randomised, placebo-controlled, double-blind pilot trial. Lancet Neurol 2009;8:48-56.

26. Shaw L, Price C, McLure S, et al. Paramedic Initiated Lisinopril for Acute Stroke Treatment (PIL-FAST): results from the pilot randomised controlled trial. Emerg Med J 2014;31:994-9.

27. Schrader J, Lüders S, Kulschewski A, et al. The ACCESS study: evaluation of acute candesartan cilexetil therapy in stroke survivors. Stroke 2003;34:1699-703.

28. Bath PMW, Martin RH, Palesch Y, et al. Effect of Telmisartan on functional outcome, recurrence, and blood pressure in patients with acute mild ischemic stroke: a PRoFESS subgroup analysis. Stroke 2009;40:3541-6.

29. Sandset EC, Bath PM, Boysen G, et al. The angiotensin-receptor blocker candesartan for treatment of acute stroke (SCAST): a randomised, placebo-controlled, double-blind trial. Lancet 2011;377:741-50.

30. Sare G, Ghandami A, Ankolekar S, et al. Effect of Telmisartan on cerebral and systemic haemodynamics in patients with recen ischaemic stroke: a randomised controlled trial. ISRN Stroke 2013:2013:9.

31. Barer DH, Cruickshank JM, Ebrahim SB, et al. Low dose beta blockade in acute stroke ("BEST" trial): an evaluation. $\mathrm{Br}$ Med $J$ (Clin Res Ed) 1988;296:737-41.

32. Wahlgren NG, MacMahon DG, De Keyser J, et al. Intravenous Nimodipine West European Stroke Trial (INWEST) of nimodipine in the treatment of acute ischaemic stroke. Cerebrovasc Dis 1994;4:204-10.

33. Horn J, de Haan RJ, Vermeulen M, et al. Very early nimodipine use in stroke (VENUS): a randomized, double-blind, placebo-controlled trial. Stroke 2001;32:461-5.

34. Horn J, Limburg M. Calcium antagonists for ischemic stroke: a systematic review. Stroke 2001;32:570-6.

35. Eames PJ, Robinson TG, Panerai RB, et al. Bendrofluazide fails to reduce elevated blood pressure levels in the immediate post-stroke period. Cerebrovasc Dis 2005;19:253-9.

36. Muir KW, Lees KR, Ford I, et al. Magnesium for acute stroke (Intravenous Magnesium Efficacy in Stroke trial): randomised controlled trial. Lancet 2004;363:439-45.

37. Saver JL, Starkman S, Eckstein M, et al. Prehospital use of magnesium sulfate as neuroprotection in acute stroke. $N$ Engl $J$ Med 2015;372:528-36.

38. Ankolekar S, Fuller M, Cross I, et al. Feasibility of an ambulance-based stroke trial, and safety of glyceryl trinitrate in ultra-acute stroke: the rapid intervention with glyceryl trinitrate in Hypertensive Stroke Trial (RIGHT, ISRCTN66434824). Stroke 2013;44:3120-8.

39. Bath PM, Woodhouse L, Scutt P, et al. Efficacy of nitric oxide, with or without continuing antihypertensive treatment, for management of high blood pressure in acute stroke (ENOS): a partial-factorial randomised controlled trial. Lancet 2015;385:617-28.

40. Hillis $\mathrm{AE}$, Ulatowski JA, Barker PB, et al. A pilot randomised trial of induced blood pressure elevation: effects on function and focal perfusion in acute and subacute stroke. Cerebrovasc Dis 2003;16:236-48.

41. Sprigg N, Willmot MR, Gray LJ, et al. Amphetamine increases blood pressure and heart rate but has no effect on motor recovery or cerebral haemodynamics in ischaemic stroke: a randomized controlled trial (ISRCTN 36285333). J Hum Hypertens 2007:21:616-24

42. Saxena $\mathrm{R}$, Wijnhoud $\mathrm{AD}$, Carton $\mathrm{H}$, et al. Controlled safety study of a hemoglobin-based oxygen carrier, DCLHb, in acute ischemic stroke. Stroke 1999;30:993-6.

43. Dyker AG, Grosset DG, Lees K. Perindopril reduces blood pressure but not cerebral blood flow in patients with recent cerebral ischemic stroke. Stroke 1997;28:580-3.

44. Eveson DJ, Robinson TG, Potter JF. Lisinopril for the treatment of hypertension within the first 24 hours of acute ischemic stroke and follow-up. Am J Hypertens 2007;20:270-7.

45. Jusufovic M, Sandset EC, Bath PMW, et al. Blood pressure lowering treatment with candesartan in patients with acute hemorrhagic stroke. Stroke 2014;45:3440-2.

46. Nakamura T, Tsutsumi $Y$, Shimizu $Y$, et al. Renin-angiotensin system blockade safely reduces blood pressure in patients with minor ischaemic stroke during the acute phase. J Stroke Cerebrovasc Dis 2010;19:435-40.

47. Beer $\mathrm{C}$, Blacker D, Bynevelt M, et al. A randomized placebo controlled trial of early treatment of acute ischemic stroke with atorvastatin and irbesartan. Int J Stroke 2012;7:104-11.

48. Oh MS, Yu KH, Hong KS, et al. Modest blood pressure reduction with valsartan in acute ischaemic stroke: a prospective, randomised, open-label, blinded-end-point trial. Int J Stroke 2015;10:745-51

49. McRitchie RJ, Chalmers JP. Paradoxical inotropic effects of clonidine and labetalol in the conscious rabbit. $J$ Cardiovasc Pharmacol 1981;3:818-27.

50. Hoffman WE, Cheng MA, Thomas $\mathrm{C}$, et al. Clonidine decreases plasma catecholamines and improves outcome from incomplete ischemia in the rat. Anesth Analg 1991;73:460-4.

51. Maier C, Steinberg GK, Sun GH, et al. Neuroprotection by the alpha 2-adrenoreceptor agonist dexmedetomidine in a focal model of cerebral ischemia. Anesthesiology 1993;79:306-12.

52. Lonn EM, Yusuf S, Jha P. Emerging role of angiotensin-converting enzyme inhibitors in cardiac and vascular protection. Circulation 1994:90:2056-68

53. Anderson C. Blood pressure-lowering for secondary prevention of stroke: ACE inhibition is the key. Stroke 2003;34:1333-4.

54. Dai WJ, Funk A, Herdegen T, et al. Blockade of central angiotensin AT(1) receptors improves neurological outcome and reduces expression of AP-1 transcription factors in after local brain ischaemia in rats. Stroke 1999;30:2319-19.

55. Iwai M, Liu HW, Chen R, et al. Possible inhibition of focal cerebral ischemia by angiotensin II type 2 receptor stimulation. Circulation 2004; $110: 843-8$

56. Bonten TN, Plaizier CE, Snoep JJ, et al. Effect of $\beta$-blockers on platelet aggregation: a systematic review and meta-analysis. $\mathrm{Br} J$ Clin Pharmacol 2014;78:940-9.

57. Bath P. Blood pressure-lowering for secondary prevention of stroke: ACE inhibition is not the key. Stroke 2003;34:1334-5.

58. Lin J-Y, Chung S-Y, Lin M-C, et al. Effects of magnesium sulfate on energy metabolites and glutamate in the cortex during focal cerebral ischemia and reperfusion in the gerbil monitored by a dual-probe microdialysis technique. Life Sci 2002;71:803-11.

59. Nowak L, Bregestovski $\mathrm{P}$, Ascher $\mathrm{P}$, et al. Magnesium gates glutamate-activated channels in mouse central neurones. Nature 1984;307:462-5.

60. Chi OZ, Pollak P, Weiss HR. Effects of magnesium sulfate and nifedipine on regional blood flow during middle cerebral artery ligation in the rat. Arch Int Pharmacodyn Ther 1990;304:196-205.

61. ISIS-4 (Fourth International Study of Infarct Survival) Collaborative Group. ISIS-4: a randomised factorial trial assessing early oral captopril, oral mononitrate, and intravenous magnesium sulphate in 58,050 patients with suspected acute myocardial infarction. Lancet 1995;345:669-85.

62. Radomski MW, Palmer RM, Moncada S. The role of nitric oxide and cGMP in platelet adhesion to vascular endothelium. Biochem Biophys Res Commun 1987;148:1482-9.

63. Bath PM, Hassall DG, Gladwin AM, et al. Nitric oxide and prostacyclin. Divergence of inhibitory effects on monocyte chemotaxis and adhesion to endothelium in vitro. Arterioscler Thromb 1991;11:254-60.

64. Butterworth RJ, Cluckie A, Jackson SHD, et al. Pathophysiological assessment of nitric oxide (given as sodium nitroprusside) in acute ischaemic stroke. Cerebrovasc Dis 1998;8:158-65.

65. Bath PMW, Pathansali R, Iddenden $\mathrm{R}$, et al. The effect of transdermal glyceryl trinitrate, a nitric oxide donor, on blood pressure and platelet function in acute stroke. Cerebrovasc Dis 2001;11:265-72. 
66. Fagan SC, Gengo FM, Bates V, et al. Effect of Nimodipine on blood pressure in acute ischemic stroke in humans. Stroke 1988;19:401-2.

67. Gelmers HJ, Gorter K, de Weerdt CJ, et al. A controlled trial of nimodipine in acute ischemic stroke. $N$ Engl $\mathrm{J}$ Med 1988;318:203-7.

68. Paci A, Ottaviano $P$, Trenta $A$, et al. Nimodipine in acute ischemic stroke: a double-blind controlled study. Acta Neurol Scand 1989;80:282-6.

69. Holthoff $\mathrm{V}$, Beil C, Hartmann-Klosterkötter $\mathrm{U}$, et al. Effect of nimodipine on glucose metabolism in the course of ischemic stroke. Stroke 1990;21:IV95-7.

70. Ahmed N, Näsman P, Wahlgren NG. Effect of intravenous nimodipine on blood pressure and outcome after acute stroke. Stroke 2000;31:1250-5.

71. Bridges SL, Koch G, Munera C, et al. Intravenous nimodipine in acute stroke: interim analysis of randomised trials. Stroke 1991;22:153.

72. Horn J, Limburg L, Orgogozo JM. Calcium antagonists for acute ischemic stroke. In: Cochrane Library, 1st edn. Oxford: Update Software, 2001.

73. Gelmers HJ, Gorter K, deWeerdt CJ, et al. Effect of nimodipine on neurological deficits and outcome of patients with acute ischemic stroke: results of a multicenter double blind placebo controlled study. J Neurol 1985;232:139.

74. Muir KW, Lees KR. Excitatory amino acid antagonists for acute stroke. Cochrane Database Syst Rev 2003;(3):CD001244.

75. Rashid P, Weaver C, Leonardi-Bee J, et al. The effects of transdermal glyceryl trinitrate, a nitric oxide donor, on blood pressure, cerebral and cardiac hemodynamics, and plasma nitric oxide levels in acute stroke. J Stroke Cerebrovasc Dis 2003;12:143-51

76. Willmot M, Ghadami A, Whysall B, et al. Transdermal glyceryl trinitrate lowers blood pressure and maintains cerebral blood flow in recent stroke. Hypertension 2006;47:1209-15.

77. Woodhouse L, Scutt P, Krishnan K, et al. Effect of hyperacute administration (within 6 hours) of transdermal glyceryl trinitrate, a nitric oxide donor, on outcome after stroke: subgroup analysis of the Efficacy of Nitric Oxide in Stroke (ENOS) trial. Stroke 2015;46:3194-201.

78. Krishnan K, Scutt P, Woodhouse L, et al. Glyceryl trinitrate for acute intracerebral haemorrhage: results from the Efficacy of Nitric Oxide in Stroke (ENOS) trial, a subgroup analysis. Stroke 2016;47:44-52.

79. Mistri AK, Robinson TG, Potter JF. Pressor therapy in acute ischaemic stroke: systematic review. Stroke 2006;37:1565-71

80. Potter J, Mistri A, Brodie F, et al. Controlling hypertension and hypotension immediately post stroke (CHHIPS) - a randomised controlled trial. Heath Technol Assess 2009;13:iii, ix-xi, 1-73.

81. Schultz S, Grady B, Cole F, et al. A role for endothelin and nitric oxide in the pressor response to diaspirin cross-linked hemoglobin. J Lab Clin Med 1993;122:301-8.

82. Sprigg N, Bath PM. Speeding stroke recovery? A systematic review of amphetamine after stroke. J Neurol Sci 2009;285:3-9.

83. He J, Zhang Y, Xu T, et al. Effects of immediate blood pressure reduction on death and major disability in patients with acute ischemic stroke: the CATIS randomized clinical trial. JAMA 2013;311:479-89

84. Koch S, Romano JG, Forteza AM, et al. Rapid blood pressure reduction in acute intracerebral hemorrhage: feasibility and safety. Neurocrit Care 2008;8:316-21.

85. Butcher KS, Jeerakathil T, Hill M, et al. The intracerebral hemorrhage acutely decreasing arterial pressure trial. Stroke 2013;44:620-6.

86. Anderson CS, Huang Y, Wang JG, et al. Intensive blood pressure reduction in acute cerebral haemorrhage trial (INTERACT): a randomised pilot trial. Lancet Neurol 2008;7:391-9.

87. Antihypertensive Treatment of Acute Cerebral Hemorrhage (ATACH) Investigators. Antihypertensive treatment of acute cerebra hemorrhage. Crit Care Med 2010;38:637-48.

88. Qureshi Al, Palesch YY, Martin R, et al. Effect of systolic blood pressure reduction on hematoma expansion, perihematomal edema, and 3-month outcome among patients with intracerebral hemorrhage: results from the antihypertensive treatment of acute cerebral hemorrhage study. Arch Neurol 2010;67:570-6.

89. Anderson CS, Heeley E, Huang $Y$, et al. Rapid blood-pressure lowering in patients with acute intracerebral hemorrhage. $N$ Engl $J$ Med 2013;368:2355-65.

90. Wang X, Arima H, Heeley E, et al. Magnitude of blood pressure reduction and clinical outcomes in acute intracerebral hemorrhage: intensive blood pressure reduction in acute cerebral hemorrhage trial study. Hypertension 2015;65:1026-32.

91. Hill MD, Muir KW. INTERACT-2: Should blood pressure be aggressively lowered acutely after intracerebral haemorrhage? Stroke 2013;44:2951-2.

92. Tsivgoulis G, Katsanos AH, Butcher KS, et al. Intensive blood pressure reduction in acute intracerebral hemorrhage: a meta-analysis. Neurology 2014;83:1523-9.

93. Carcel C, Wang X, Sato S, et al. Degree and timing of intensive blood pressure lowering on hematoma growth in intracerebral hemorrhage: intensive blood pressure reduction in acute cerebral hemorrhage trial-2 results. Stroke 2016;47: 1651-1653.

94. Jauch EC, Saver JL, Adams HP, Jr. et al. Guidelines for the early management of patients with acute ischemic stroke: a guideline for healthcare professionals from the American Heart Association/ American Stroke Association. Stroke 2013;44:870-947.

95. Intercollegiate Stroke Working Party. National clinical guideline for stroke, 4th edn. Royal College of Physicians 2012.

96. Hacke W, Ringleb PA, Bousser MG, et al. Guidelines for management of ischaemic stroke and transient ischaemic attack 2008 -the European Stroke Organisation (ESO) Executive Committee and the ESO Writing Committee. Cerebrovasc Dis 2008;25: 457-507.

97. The GUSTO Investigators. An international randomized trial comparing four thrombolytic strategies for acute myocardial infarction. N Engl J Med 1993;329:673-82.

98. The TIMI Study Group. Comparison of invasive and conservative strategies after treatment with intravenous tissue plasminogen activator in acute myocardial infarction. Results of the thrombolysis in myocardial infarction (TIMI) phase II trial. N Engl J Med 1989;320:618-27.

99. Wahlgren N, Ahmed N, Eriksson N, et al. Multivariable analysis of outcome predictors and adjustment of main outcome results to baseline data profile in randomized controlled trials: Safe Implementation of Thrombolysis in Stroke-MOnitoring STudy (SITS-MOST). Stroke 2008;39:3316-22.

100. Ahmed N, Wahlgren N, Brainin M, et al. Relationship of blood pressure, antihypertensive therapy, and outcome in ischemic stroke treated with intravenous thrombolysis: retrospective analysis from Safe Implementation of Thrombolysis in Stroke-International Stroke Thrombolysis Register (SITS-ISTR). Stroke 2009;40:2442-9.

101. Huang Y, Sharma VK, Robinson T, et al. Rationale, design, and progress of the ENhanced Control of Hypertension ANdThrombolysis strokE stuDy (ENCHANTED) trial: an international multicenter $2 \times 2$ quasi-factorial randomized controlled trial of low- vs. standard-dose rt-PA and early intensive vs. guideline-recommended blood pressure lowering in patients with acute ischaemic stroke eligible for thrombolysis treatment. Int $J$ Stroke 2015;10:778-88.

102. Hemphill JC, Greenberg SM, Anderson CS, et al. Guidelines for the management of spontaneous intracerebral hemorrhage. Stroke 2015;46:2032-60.

103. Steiner T, Al-Shahi Salman R, Beer R, et al. European Stroke Organisation (ESO) guidelines for the management of spontaneous intracerebral hemorrhage. Int J Stroke 2014;9:840-55.

104. Tsai CF, Thomas B, Sudlow CLM. Epidemiology of stroke and its subtypes in Chinese vs white populations: a systematic review. Neurology 2013;81:264-72.

105. Saver JL. Blood pressure management in early ischemic stroke. JAMA 2014;311:469-70.

106. Rothwell PM, Howard SC, Spence JD. Relationship between blood pressure and stroke risk in patients with symptomatic carotid occlusive disease. Stroke 2003;34:2583-90.

107. Jusufovic M, Sandset EC, Bath PMW, et al. Effects of blood pressure lowering in patients with acute ischemic stroke and carotid artery stenosis. Int $J$ Stroke 2015;10:354-9.

108. Goyal M, Menon BK, van Zwam WH, et al. Endovascular thrombectomy after large-vessel ischaemic stroke: a meta-analysis of individual patient data from five randomised trials. Lancet 2016;387:1723-31.

109. Davis MJ, Menon BK, Baghirzada LB, et al. Anesthetic management and outcome in patients during endovascular therapy for acute stroke. Anesthesiology 2012;116:396-405.

110. Robinson TG, Potter JF, Ford GA, et al. Effects of antihypertensive treatment after acute stroke in the Continue Or Stop post-Stroke Antihypertensives Collaborative Study (COSSACS): a prospective, randomised, open, blinded-endpoint trial. Lancet Neurol 2010;9:767-75. 